\title{
Estimating Structure Response and Progressive Failure of a Ship Hull under Side-Bow Collisions
}

\author{
Aditya Rio PRABOWO, Jung Min SOHN, Dong Myung BAE, Joung Hyung CHO
}

\begin{abstract}
This paper presents an analysis of the side hull in marine steel structures under accidental collision phenomena. The type of side collision considered in this work is where the striking ship penetrates the struck ship. First, the configuration of the collision phenomenon is defined, including the ship geometry, mechanical properties of the material, and applied parameters. The collision scenarios are built by applying external dynamic parameters, including target location and striking velocity. Impact locations are determined on three different regions of the struck ship's side hull: the fore-end, middle-hull, and after-end regions. These are discussed, followed by results based on the applied velocity. Second, the tendency of the collision energy is evaluated to observe the structural behaviour on the struck ship's side hull during penetration by the striking ship. Progressive failure is summarised based on the results of two parameters, and $f$ the material model is confirmed by comparing the collision energy with pioneering work on ship collision.
\end{abstract}

Keywords: accidental ship collision; crashworthy ship structures; finite element analysis; material sensitivity; progressive failure

\section{INTRODUCTION}

Collisions between marine structures (namely ships) are an increasing concern in many countries. The impact of such an event can be prioritised according to the following: human life, the marine environment, and the involved structures themselves. To illustrate, respectively, the catastrophic accident of the Titanic in 1912 resulted in the death of more than half of its passengers; the environmental disaster of the Exxon Valdez (1989) collision resulted in a major oil spill of over 10 million gallons; in 2014 the cargo reefer Qi Hang collided with a passenger vessel Marisa Nusantara in the Sunda Strait. Impacts with marine structures have been taken seriously by related parties for the following reasons: to provide investigation procedures, to make predictions in structural assessment to provide an understanding of hazardous damages [1], and to make technical recommendations to reduce casualties. Most studies were generally performed based on the assumption of a physical event.

Previous work in this field was conducted using the finite-element method (FEM), such as studies on ship-ship collision [2] and ice-structure interaction [3]. Statistics of expected pollution after collision events were presented by Yip et al. [4], while a comparative study of structural response subjected to collision parameters was done by Prabowo [5] and Lützen [6] using analytical and probabilistic methods, respectively. Although many impact-related studies have been conducted, quantification of structural failure and its correlation with the behaviour of crash-worthy ship hulls has not yet been discussed in detail. This is especially true for marine structures intended for special purposes and designed using rules without referring to Common Structural Rules (CSRs), for example passenger ships. Thus, sustainable studies to continue the work in the above studies of assessing impacted marine steel structures are considered.

The aim of the present work is to perform collision damage modelling and observe the structural behaviours of Roll-on/Roll-off (RoRo) passenger ships, accounting for the applied external parameters, meaning collision location and striking velocity. The effect of the external part will be quantified considering a variety of structural arrangements along the hull. Crash worthiness criteria are discussed to provide adequate estimation of the struck ship's behaviours. The event sequence when members of the side hull experience rupture is summarised after evaluation of the after-end, midsection, and fore-end regions.

\section{CALCULATION METHOD FOR ACCIDENTAL COLLISION ANALYSIS}

Ship collision is considered an accidental event in the field of marine engineering. This phenomenon is complex, because various parameters may be involved in a single collision case. In an effort to simplify a collision, the simplified coordinate system (Fig. 1), is presented. As stated in Newton's third law of motion, for every action, there is an equal and opposite reaction. This law indicates that every physical contact to an object involves action and reaction phenomena.

This concept is also applied in ship collisions, and it is divided into two parts - external dynamics and internal mechanics of ship collisions - as stated in pioneering works such as that by Ozguc [7]. The external dynamics consist of several parameters, including location and velocity, considered as actions in the current work. However, ship collisions also possess internal mechanics in which the implementation of a parameter focuses on the internal part of the side hull, such as steel material and a double-hull configuration.
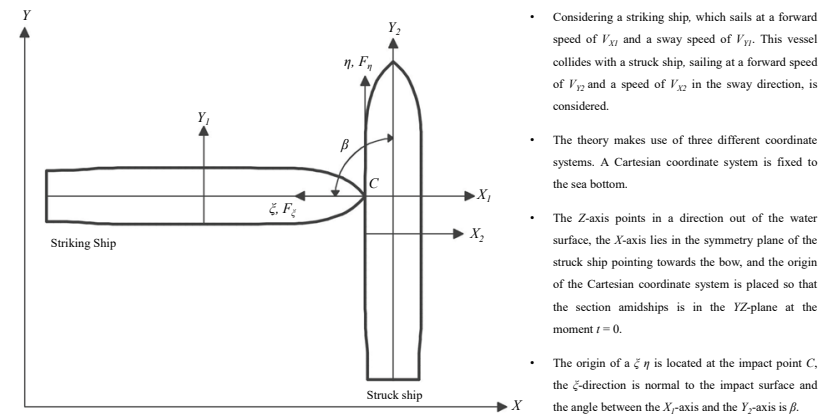

Figure 1 Simplified coordinate system of a ship collision

Observations of collisions have been performed since the $19^{\text {th }}$ century. At that time, Minorsky [8] observed the characteristics of energy absorption from 26 full-scale ship collision cases. This observation was concluded in the form 
of an empirical formula. Further development was conducted to refine the accuracy of the formula, such as the work of Zhang [9]. A notable trend related to impact phenomena, considering effectiveness in terms of time and cost, is experimental testing, preferably conducted by scaled model tests $[10,11]$. In early 2000 , improvements of computational technology and calculation algorithms resulted in this tendency accelerating, and numerical has become a new evaluation strategy to obtain predicted data for almost all science and engineering phenomena.

The FEM is considered a powerful method to solve the analysis of structural responses [12, 13]. Further improvement in computing engineering make it possible to use this method to simulate highly nonlinear problems, including collisions [14], grounding [15], and explosions [16]. Because of its nature as a numerical method, better instruments will make the modelling process easier and produce confident results in an acceptable operating time. However, a challenge of this method is to obtain reliable results from numerical simulations based on physical phenomena. The numerical model for an analysis does not need all specific details of the physical model. The user can define the parts that will represent the actual model, so that the FEM can produce a result that has good correlation with the actual model in an acceptable time [17]. In collision analysis by numerical methods, the explicit methodology can be considered a good option. The collision, grounding, and other impact analyses that involve high nonlinearity and need a small time step are suitable for the characteristics of this methodology.

\section{MATERIAL SENSITIVITY IN NONLINEAR PHENOMENA}

Influence of several factors is significant for the behaviour of metallic materials. A previous study by Jones indicated that the increment of mild steel was observed as the strain rate increased (see stress-strain curve for mild steel at various strain rates in Jones [18]). However, it was noted that aluminium is not particularly affected by the strain rate in normal practice. The strain rate itself is often defined using the Cowper-Symonds parameter, for example as incorporated in explicit finite-element codes to solve nonlinear structural problems. The parameter was originally described in an empirical expression, as shown in Eq. (1), to scale the yield stress and estimate the total strain rate effect [19]. However, it is a challenging task, and very time consuming, to consider the effect of the strain rate in accidental impacts. Zhang [9] used the mathematical assumption in Eq. (2) as flow stress for further analytical and empirical estimation. For mild steel, the CowperSymonds parameters $C=40.4 \mathrm{~s}^{-1}$ and $P=5$ are recommended as reasonable values in material characterisation [20]. An essential factor in impact damage modelling (collision and grounding) is the nature of the impact as a nonlinear event causing a high structural dynamic. At the end of penetration by an indenter, a large damage extent could take place. In this condition, a greater value of the Cowper-Symonds parameter $C$ is often preferred (see the structural crashworthiness study by Törnqvist [21]). For an example of this assumption, during experimental testing of stiffened panels by Alsos and Amdahl [22], $C=4000 \mathrm{~s}^{-1}$ was applied, and $C=3200 \mathrm{~s}^{-1}$ was used by Prabowo et al. [23] for collision analysis.

$$
\begin{aligned}
& \frac{\sigma_{e q}^{D}}{\sigma_{e q}}=1+\left(\frac{\dot{\varepsilon}_{e q}}{C}\right)^{\frac{1}{m}} \\
& \sigma_{0}=\frac{1}{2}\left(\sigma_{Y}+\sigma_{U}\right)
\end{aligned}
$$

where $\sigma_{e q}^{D}$ is the dynamic flow stress; $\sigma_{e q}$ is the quasi-static equivalent flow stress; $C$ and $m$ are constants so called Cowper-Symonds parameters $C$ and $P$ in various literature; $\sigma_{Y}$ is the yield stress and $\sigma_{U}$ is the ultimate stress. The terminologies $\sigma_{e q}^{D}$ and $\sigma_{e q}$ were denoted as $\sigma_{0}^{d}$ and $\sigma_{0}$ in [9]).

Simonsen [24] mentioned that it is impossible to trace the strain history of material elements at a very detailed level. Therefore, many preceding scholars, such as Wang [25] used the maximum strain limit criterion to model material failure in impact engineering and analysis. To determine the strain value, several tests and experiments were used. Wen and Jones [26] showed that the tensile ductility of mild steel was in the range of $0.20-0.35$. Application of this experimental result in the early 20th century was described in a previous study by Ozguc [7] for structural assessment of single- and double-hull bulk carriers. Collaboration with nonlinear-inelastic material model is ideal to be implemented for the failure strain in the analysis.

\section{FE MODELLING AND ANALYSIS PREPARATION 4.1 Ship Geometry and Material}

A collision incident involving a RoRo and cargo reefer was considered as a reference for the numerical simulation. The RoRo passenger ship was the steel-plated structure of the struck ship. Meanwhile, the cargo reefer acted as a striking bow to penetrate the struck ship. This entity was modelled as a rigid body to focus all the damages that occurred on the struck ship. The principal dimensions for both the struck ship and the striking bow are presented in Tabs. 1 and 2. During the collision analysis, the steel-plated hull of the struck ship was divided into three regions: foreend, midsection, and after-end (Figs. 2a-c). The geometry of the striking bow is shown in Fig. 2d.

Table 1 Principal dimensions of the struck ship

\begin{tabular}{|l|c|}
\hline \multicolumn{1}{|c|}{ Characteristic } & Type and Value \\
\hline Type of ship & Ro-Ro passenger \\
\hline Length over all $(\mathrm{m})$ & 85.92 \\
\hline Length between perpendicular $(\mathrm{m})$ & 78.00 \\
\hline Breadth moulded $(\mathrm{m})$ & 15.00 \\
\hline Design draft $(\mathrm{m})$ & 4.30 \\
\hline Depth $(\mathrm{m})$ & 10.40 \\
\hline
\end{tabular}

Table 2 Principal dimensions of the striking ship

\begin{tabular}{|l|c|}
\hline \multicolumn{1}{|c|}{ Characteristic } & Type and Value \\
\hline Type of ship & Reefer \\
\hline Length over all $(\mathrm{m})$ & 144.50 \\
\hline Breadth moulded $(\mathrm{m})$ & 19.80 \\
\hline Design draft $(\mathrm{m})$ & 5.60 \\
\hline Depth $(\mathrm{m})$ & 10.20 \\
\hline
\end{tabular}

The element-length-to-thickness (ELT) ratio was applied in the models in which 548,000 shell elements were obtained. The definition of the ship material was applied 
based on mechanical testing of a specimen from a previous collision incident on the Sunda Strait. Because the specimen was very limited, non-destructive tests, such as hardness tests and chemical composition experiments, were conducted to characterise the specimen, instead of tensile test (destructive test). The mechanical properties were determined by comparing the test results and carbon material standard. It was concluded that the specimen is a match with medium-carbon steel 1030 [27]. Modelling of the material behaviour in the simulation was performed by inputting the required coefficients of the plastic-kinematic model [28] according to the properties of the mediumcarbon steel 1030, as presented in Tab. 3. This method was considered more practical in this work than applying the material behaviour of the compressive and tensile stressstrain, because laboratory experiments to conduct tensile and compressive tests are quite extensive.

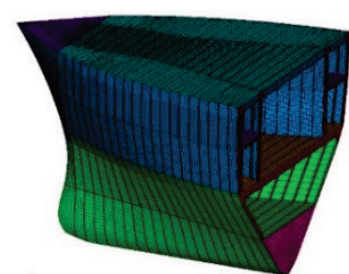

a)

c)

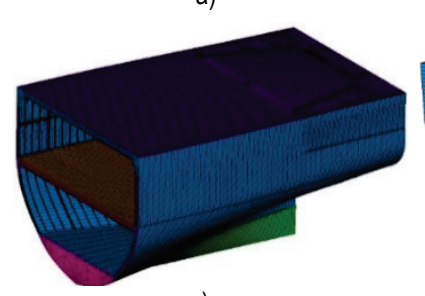

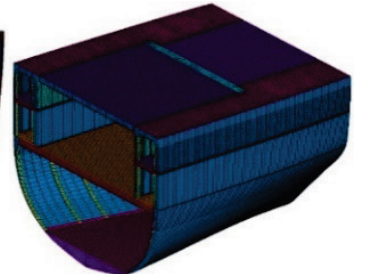

b)

d)

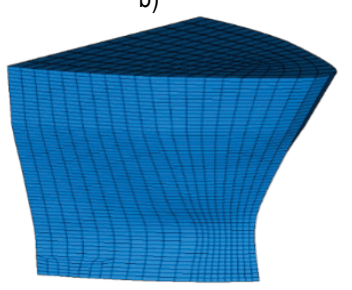

Figure 2 Geometrical model of the involved ships. The deformable struck ship is divided into three regions: (a) fore-end, (b) midsection, (c) after-end. Presented model (d) is the striking ship

Table 3 Material model for the collision analysis

\begin{tabular}{|l|c|}
\hline \multicolumn{1}{|c|}{ Properties } & Value \\
\hline Density $\left(\mathrm{kg} / \mathrm{m}^{3}\right)$ & 7850 \\
\hline Young's modulus $(\mathrm{MPa})$ & 210,000 \\
\hline Poisson's ratio $(-)$ & 0.30 \\
\hline Yield stress $(\mathrm{MPa})$ & 440 \\
\hline Failure strain $(-)$ & 0.20 \\
\hline Cowper-Symonds strain rate $-C\left(\mathrm{~s}^{-1}\right)$ & 3200 \\
\hline Cowper-Symonds strain rate $-q(-)$ & 5 \\
\hline
\end{tabular}

Simulation in the present study was performed by ANSYS LS-DYNA [28]. Models of the involved ships were built using the Belytschko-Tsay element formulation with one integration point in the plane and five integration points through thickness. To obtain reliable results, the deformation contour must be captured well during the collision. Therefore, fine mesh elements with ELT ratios of 8 for the contact area, 9 for the transition area, and 10 for the outer area were applied. This ratio represents the density of mesh size relative to the thickness of the object. The ratio 8 means that the contact area was applied with the smallest mesh size compared with the transition and outer areas. Contact was modelled between the striking and struck ships' bodies, where the friction coefficient was assumed to be the used coefficient value of friction between mild steels with $\mu_{s}=0.74$ and $\mu_{k}=0.57$.
$\sigma_{Y}=\left[1+\left(\frac{\dot{\varepsilon}}{C}\right)^{\frac{1}{P}}\right]\left(\sigma_{0}+\beta E_{p} \varepsilon_{p}^{e f f}\right)$

where $\sigma_{Y}$ is the yield stress, $\varepsilon$ is the strain rate, $C$ is the Cowper-Symonds strain rate parameters, $P$ is the Cowper Symonds strain rate parameters, $\sigma_{0}$ is the initial yield stress, $\beta$ is the hardening parameter, $E_{p}$ is the plastic hardening modulus, and $\varepsilon_{p}^{e f f}$ is the effective plastic strain.

The deformable material for the struck ship was modelled by the plastic-kinematic material proposed by Krieg and Key [29] regarding implementation of a timedependent plasticity theory in a structural program. This model is embedded with strain dependency and failure. Assumptions of isotropic and kinematic may be defined by adjusting hardening parameters. In this study, a kinematic hardening model was applied to the material. The strain rate was applied using the Cowper-Symonds model, which calculates the yield stress by the given expression in Eq. (3). Strain rate effects were included in the material model with $C=3200\left(\mathrm{~s}^{-1}\right)$ and $P=5(-)$. This material is suitable for nonlinear analysis in which the observation subject experiences remarkable destruction in a plastic state while the time-dependent match the dynamic characteristics in the collision. Pioneering work [30] in impact engineering has considered the plastic-kinematic model for ship material, and it is judged satisfactory in representing overall structural behaviour under impact.

\subsection{Designed Collision Scenario}

The boundary conditions (Fig. 3) were applied on the end of the struck ship's model, according to a recent recommendation of Prabowo, which was set to be fixed on the centreline, and the end of model was clamped [31,32]. The fixation was applied on the transverse frames, and the axial displacement of the longitudinal members was restrained. Based on design research on ships transporting nuclear materials, the crashworthiness of these ships under worst-case conditions was the primary concern. A totally inelastic right-angle collision with the struck ship at rest was considered the worst case. Hence, the majority of currently available models consider only right-angle collisions and assume that the kinetic energy parallel to the struck ship's centerline is negligible. In this study, this concept was applied to the involved ships where the struck ship is standstill in the collision process, while the striking ship penetrates the struck ship while its rotation is assumed to be zero. The most popular of these approaches is the one proposed by Minorsky which is based on several assumptions: the collision is completely inelastic, the system kinetic energy along the struck ship's longitudinal direction is negligible [33] and the rotations of the struck and striking ships are small and can be neglected.

This study was conducted in three phases. The first phase involved observing the influence of the structural behaviour under collision on different longitudinal locations. Two points were set on each region as the target of the striking ship. The distance between the two points was determined between the two closest web frames to 
observe the structural behaviour under ship collisions on different longitudinal locations. The striking ship was given a constant velocity to move to the target point located between the middle and main decks on the side hull of the struck ship, while the collision angle was assumed to be perpendicular or $\beta=90^{\circ}$ (see Fig. 4a). For the striking ship's destination, two targets are determined on two web frames and denoted as Targets 1 and 2, consecutively (Fig. 4b). A similar way to determine the targets was also applied for the middle-hull and after-end. In this stage, the collision scenario was an extension of the work of Prabowo et al. [34], which discussed material behaviour during side collision. The same applied velocity of $12 \mathrm{kts}$ was used in the current work. A comparative study on the collision energy from both studies is presented in the next section.

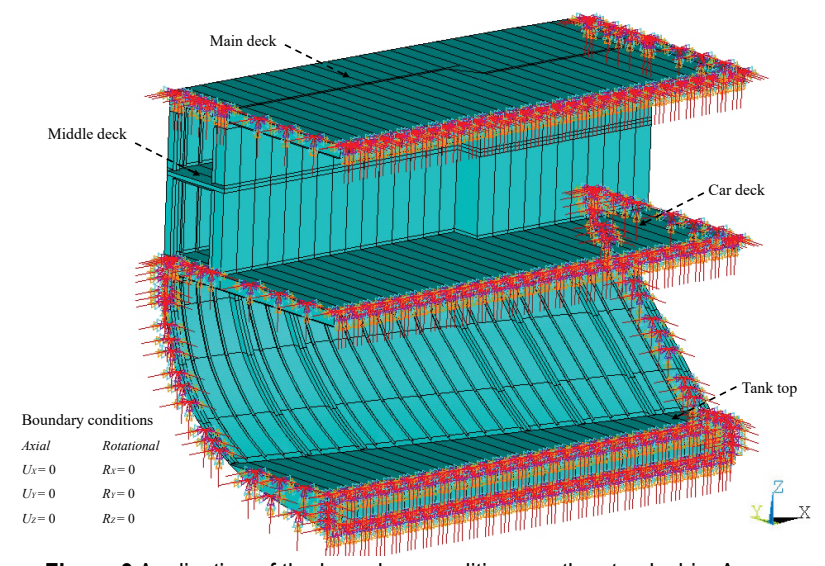

Figure 3 Application of the boundary conditions on the struck ship. Arrows denote location of the boundaries.

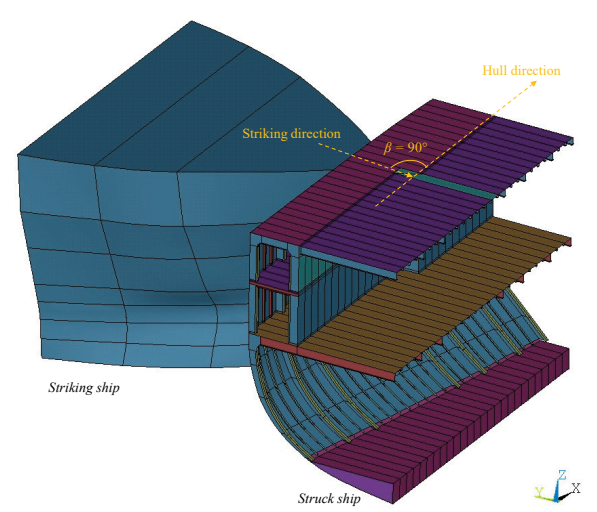

a)

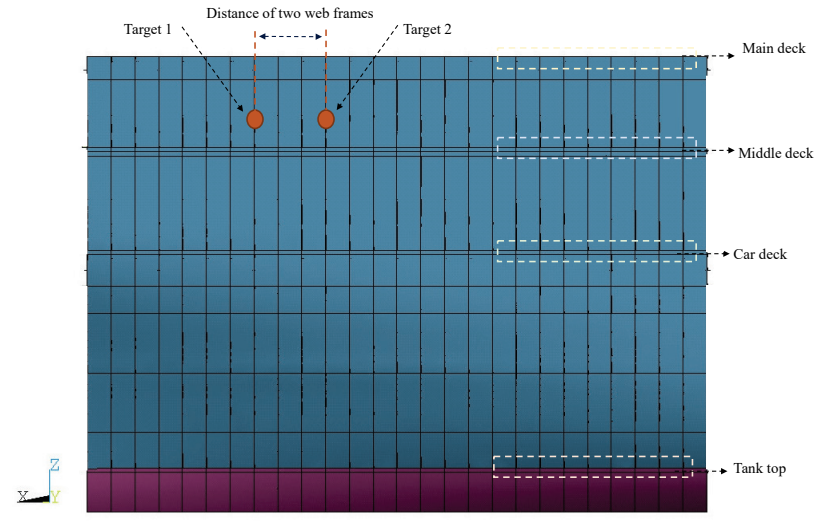

b)

Figure 4 The designed scenario for the collision analysis: (a) configuration of collision angle, and (b) bullets highlight target locations on the struck ship

In the second phase, other scenarios were defined in order to present a variety of collision models based on the velocity of the striking ship. Three velocities were applied: 5,10 , and $15 \mathrm{kts}$ for the nautical unit or $2.57,5.14$, and 7.71 $\mathrm{m} / \mathrm{s}$ in the international standard. The target in this study was determined to be one per region. After the first and second phases were conducted, the final phase was performed to observe and quantify the progressive failure on the struck ship under side collision. Failures of the structural components, such as the side shell, web frame, and main frame, are described, and their relations to the structural behaviour, i.e., energy, are also compared with pioneer studies.

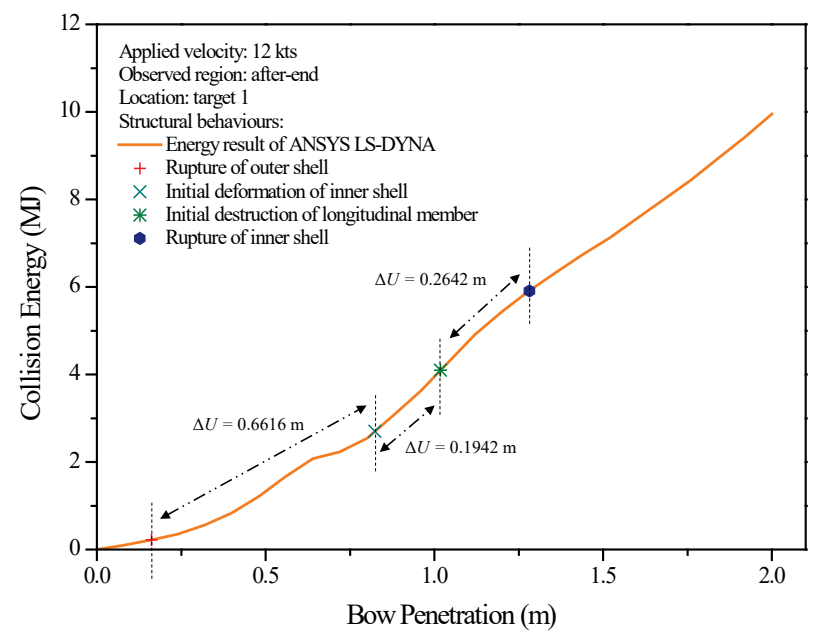

a)

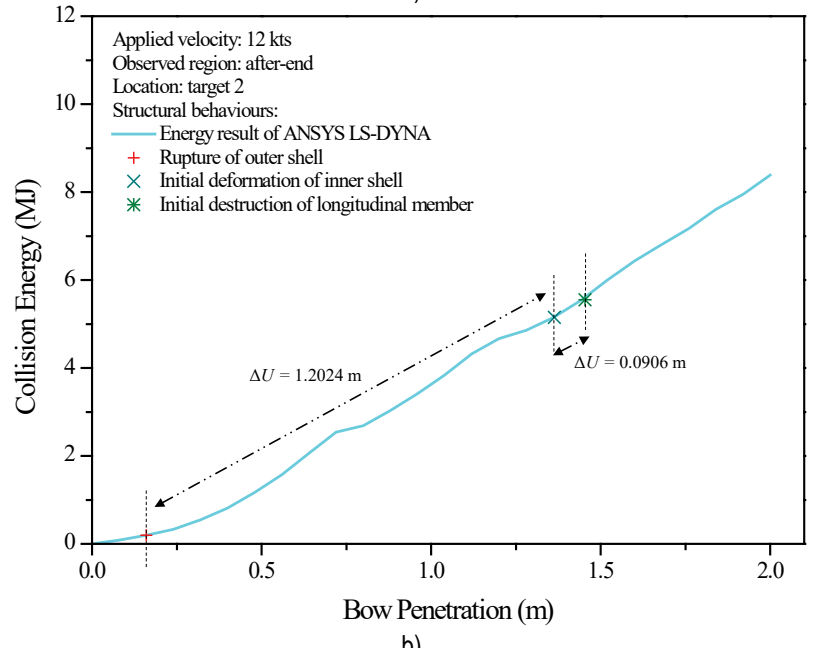

b)

Figure 5 Structural behaviours on the after-end: (a) target 1 and (b) target 2

\section{CALCULATION RESULTS AND DISCUSSIONS}

5.1 Structural Behaviour and Failure: Location and Velocity

The collision energy for the target locations on different regions is presented in the initial part of this section. This energy denotes the internal energy produced by numerical simulation using the finite-element (FE) codes. It represents the amount of energy to be used to deform the deformable structure plastically. It also provides an estimation of the absorbed strain energy by the involved structures in contact.

Because only the struck ship was assumed to be plastically deformable in this analysis, the energy indicates the structural behaviour and failure on the struck ship. Several indications of structural failure are summarised on 
the collision energy's increment as a crashworthiness criterion. As shown in Fig. 2 for the geometrical model of the struck ship, certain regions have different structural arrangements, i.e., the fore-end and midsection have a double-hull structure, whereas the after-end is a single hull. Therefore, it is necessary to conduct overall observation of the struck ship's hull. The after-end region is shown in Fig.5, the midsection is shown in Fig. 6, and the tendency of the fore-end region is shown in Fig. 7.

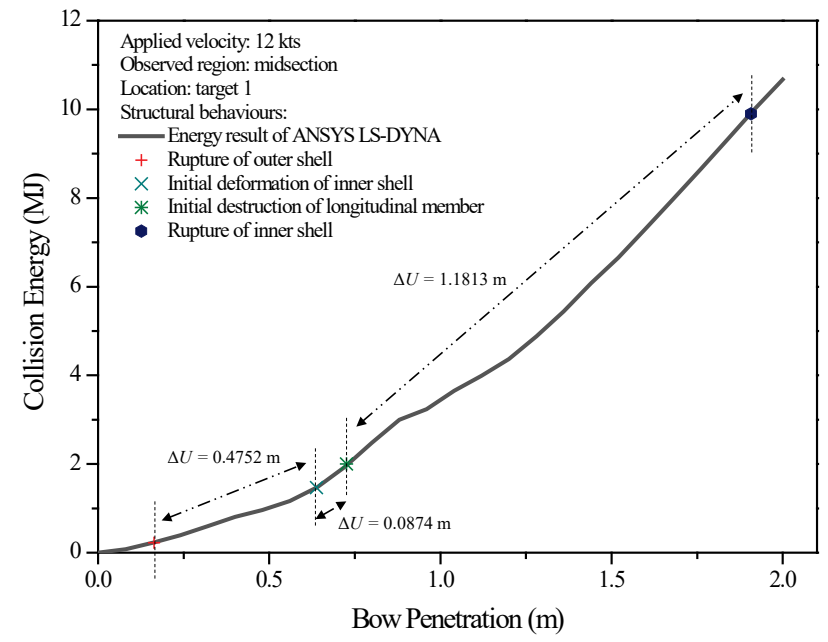

a)

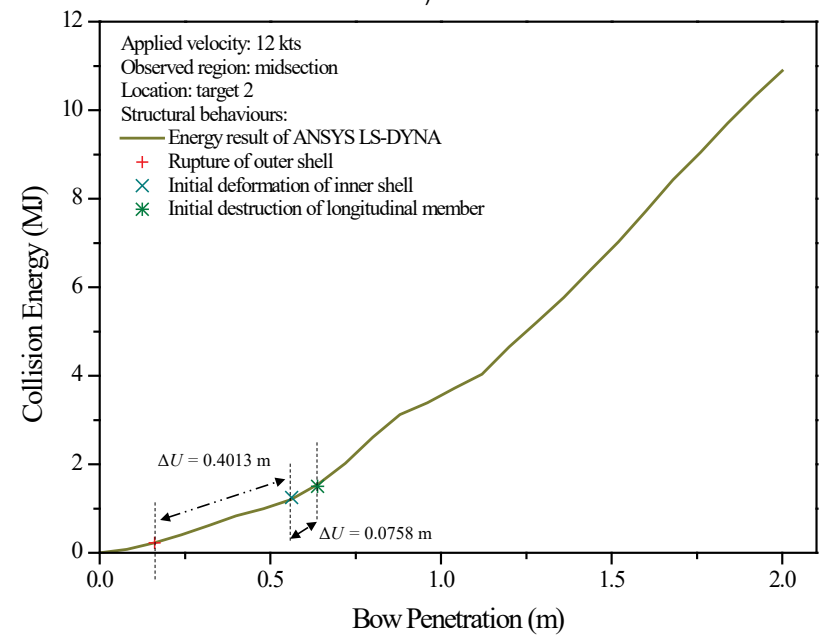

b)

Figure 6 Structural behaviours on the midsection: (a) target 1 and (b) target 2

These results represent variety of structural behaviours in three regions. The behaviours accounting for the collision energy are summarised as follows:

1) Deformation of the outer shell;

2) Rupture of the outer shell;

3) Deformation of the inner shell;

4) Deformation of the longitudinal member between the inner and outer shell, in this collision the middle deck and side stringer;

5) Destruction or rupture of the middle deck and side stringer; and

6) Rupture of the inner shell.

In terms of the striking ship's velocity during contact with the struck ship, the results of numerical analysis are presented in Fig. 8 for collision with $V=5 \mathrm{kts}$ on the afterend region. The other results are presented in Figs. 9 and 10 for the applied velocities 10 and $15 \mathrm{kts}$, respectively.
More details on the collision energy for each region with different velocities are given in Appendix A.

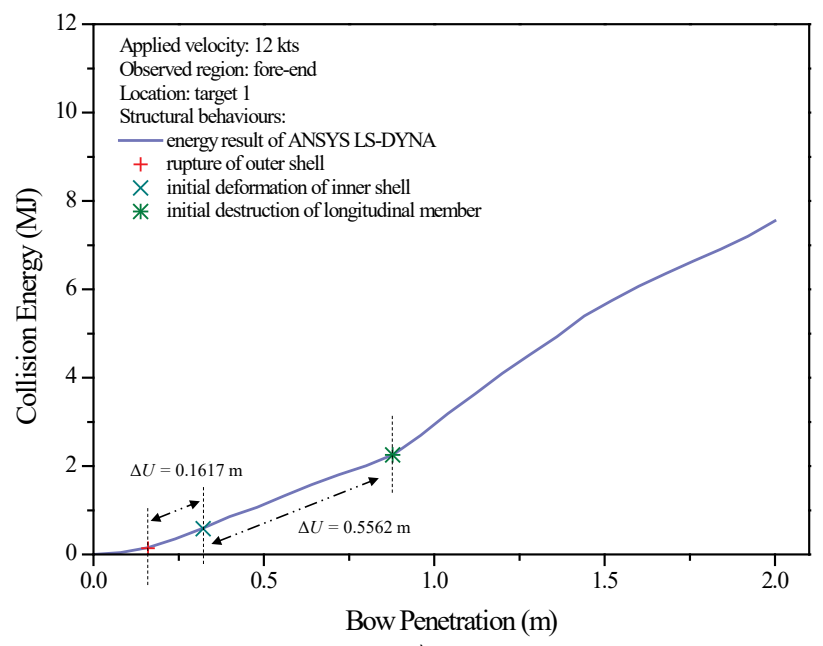

a)

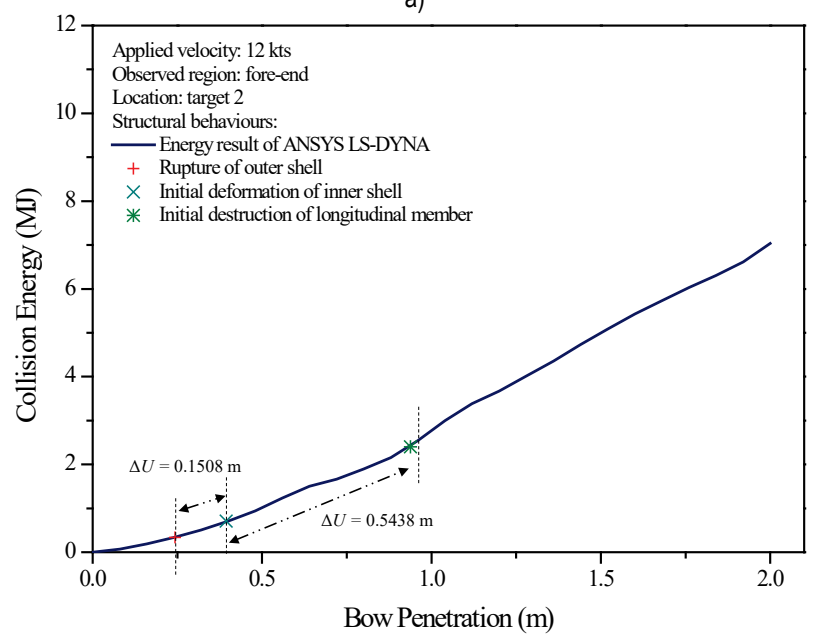

b)

Figure 7 Structural behaviours on the fore-end: (a) target 1 and (b) target 2

A summary of the energy (trend line of the kinetic and collision energy in Figs. 8 to 10) indicated that the increment of the kinetic energy caused by velocity variations was equally perpendicular with deeper penetration and higher collision energy. Besides reflecting the maximum damage extent on the side structures, the collision energy in the deepest bow penetration provided an indication of the structural strength against marine accidental load.

It was found that the middle structure was the strongest among all regions. This result corresponded to the tendency of the longitudinal strength, which due to this performance-based criterion, and the midsection was highly resistant when subjected to failure. If a failure occurs in this section, more energy is needed than the amount for indenting other regions. Increments of the kinetic energy were produced, because uniform velocity was given to the striking ship, and nonlinearities of the structural arrangement due to local indentation with deeper bow penetration caused fluctuation of the kinetic energy. Therefore, as a consequence of uniform velocity, the kinetic energy was increased instead of reduced in the side impact. Further explanations regarding structural resistance are presented in the coming discussion. 


\subsection{Structural Resistance Related to Energy Characteristics}

In the graphs of the collision energy (Figs. 5 to 7), the deformation of the outer shell is not shown, because the deformation began several seconds after the striking bow and struck ship contacted each other or, in other words, it happened shortly after collision started. The middle deck and side stringer dominated the deformation and rupture of the longitudinal members. Only these members were highly involved in the deformation process, because the struck ship was built using transverse framing systems.

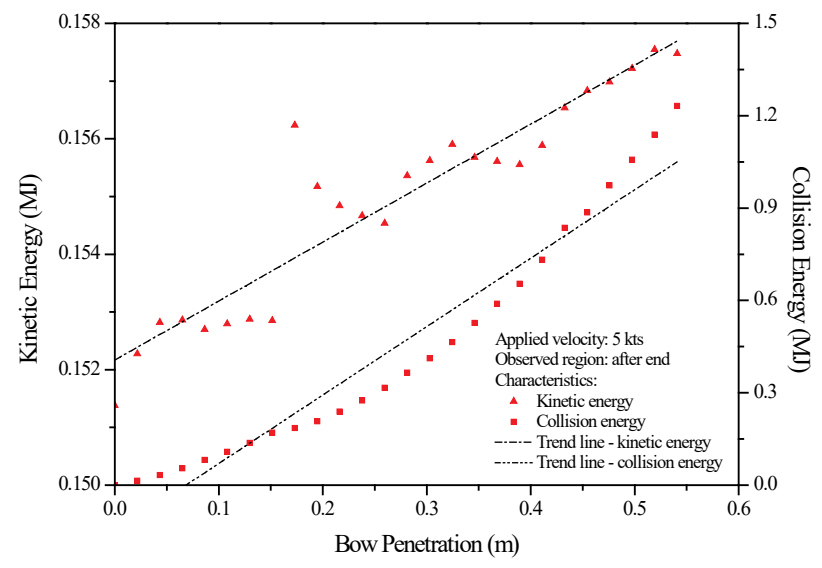

Figure 8 Energy characteristic of the impacted after-end region: the applied velocity $5 \mathrm{kts}$

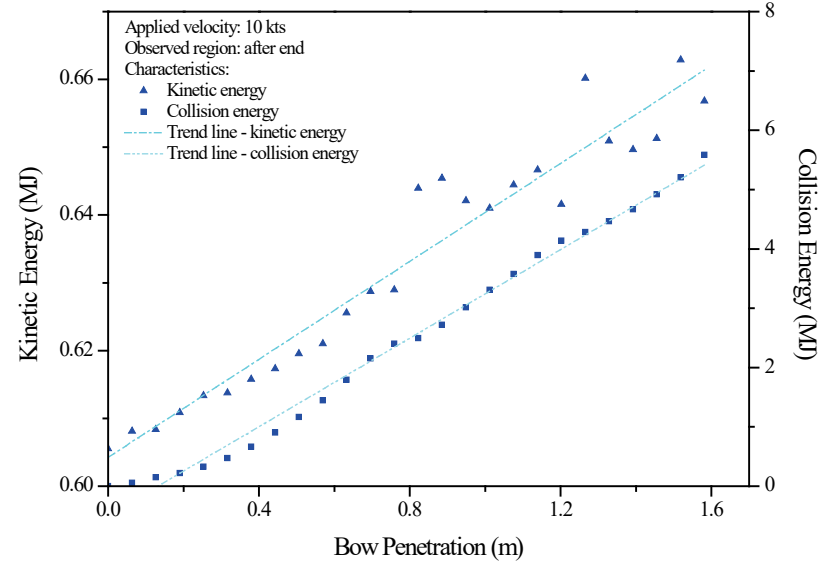

Figure 9 Energy characteristic of the impacted after-end region: the applied velocity $10 \mathrm{kts}$

The rupture of the inner shell is the main part of this observation, since the safety of the passengers' cargo on the car deck can be disturbed if the inner shell ruptures because of impact on the side structure. In several locations, the rupture of the inner shell did not occur during and after the collision process, such as in the fore-end. The collision on the fore-end region (Fig. 7) produced no rupture on the inner shell, while on the after-end (Fig. 5) and midsection (Fig. 6) and one target on each region produced rupture on the inner shell. Although the locations of the two target points were not significantly far apart, the tendency of the collision energy indicated a difference.

The various results on the structural behaviour as well as the collision energy were predicted to be influenced by the difference of the structural pattern of each region of the struck ship. The implementation of the transverse framing systems on the struck ship made a framing pattern on the side hull that was not constant. An example of this implementation could be found on the distance between two web frames. The distance of two web frames was found to be different from that of one frame to the other, or it can be said that the sum of ordinary frames between two web frames was different in each region.

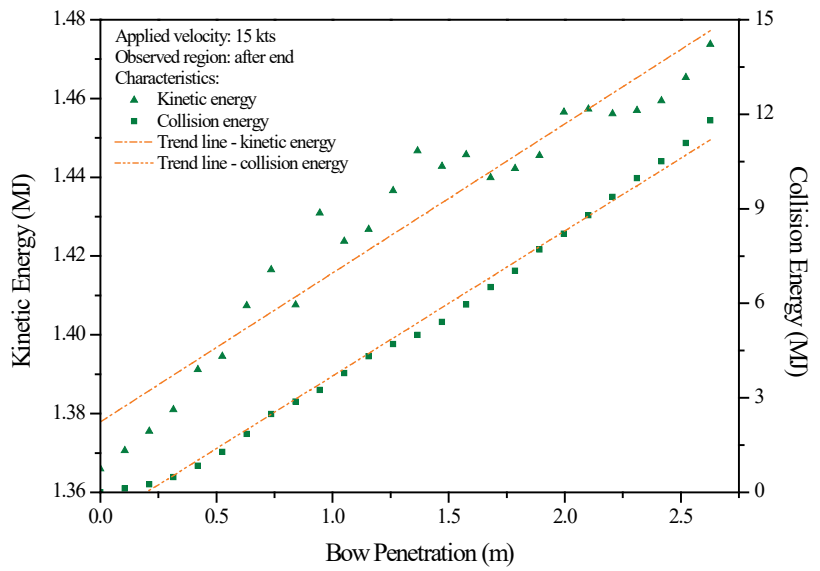

Figure 10 Energy characteristic of the impacted after-end region: the applied velocity $15 \mathrm{kts}$

A satisfactory result was also reached on the applied material in this research. Concern on the material strength's influence on the structural damage has been addressed in a series of collision simulations [34] by deploying low-carbon and high-carbon steels on the side structure to be evaluated against ship-ship impact. Similar material configurations to those in the pioneering work (i.e., Poisson's ratio, Young's modulus, and failure strain) were embedded in the struck ship in the current work. The locations for both studies were determined to be similar on the fore-end region at Target 1. It was successfully confirmed that this work, which used material 1030, produced collision energy of approximately 7.8 MJ. This value is lower than that of the applied high-carbon steel 1080 , with a yield strength of $480 \mathrm{MPa}$, and higher than that of low-carbon steel 1010, with yield strength of 180 $\mathrm{MPa}$. The collision energy was found to be $12 \mathrm{MJ}$ and 2.8 MJ for high-carbon and low-carbon steels, respectively. Further validation was also obtained from the penetration depth in that, for the same applied velocity (12 kts) on the striking ship, penetration arrived at a similar depth $(2 \mathrm{~m})$. Material strength was also determined to be the most influencing parameter among the material properties, and it was validated based on this comparison that higher yield strength produces higher collision energy.

In terms of the striking velocity, the results indicated that the velocity in side collisions is directly proportional to the depth of penetration in the struck ship and collision energy during the collision process. Furthermore, the depth of penetration influences the amount of destroyed material, because deeper penetration of the struck ship produces more destroyed material. The destroyed material itself has a direct correlation to the collision energy level.

The present results show good agreement with the theory of collision damage and energy absorption analysis, such as that of Zhang [9] and Zhang and Pedersen [35]. Conducting future studies to define collision conditions to obtain a similar result to the empirical formula is recommended. The kinetic energy in this discussion (Figs. 
8 to 10 ) represented the energy of the striking ship when it was impacting the struck ship. The fluctuation in the results indicated that, after several meters of penetration, the kinetic energy rose and reduced at certain locations. When the energy rose, it implied that the structure on that location needed higher energy to be penetrated or the structure to be more robust than other structures at different locations. The reduction of energy occurred after the penetrated structure experienced rupture. This phenomenon is illustrated in Fig.
11. The behaviour of the kinetic energy was found to increase as penetration deepened, because a constant velocity was used in the collision scenario. If an initial velocity is applied, the kinetic energy reduces in the penetration process. A constant velocity was chosen to observe the most extreme condition that could be experienced by the side hull (outer and inner hulls), where the striking ship does not slow down and keeps penetrating the target during side collision.

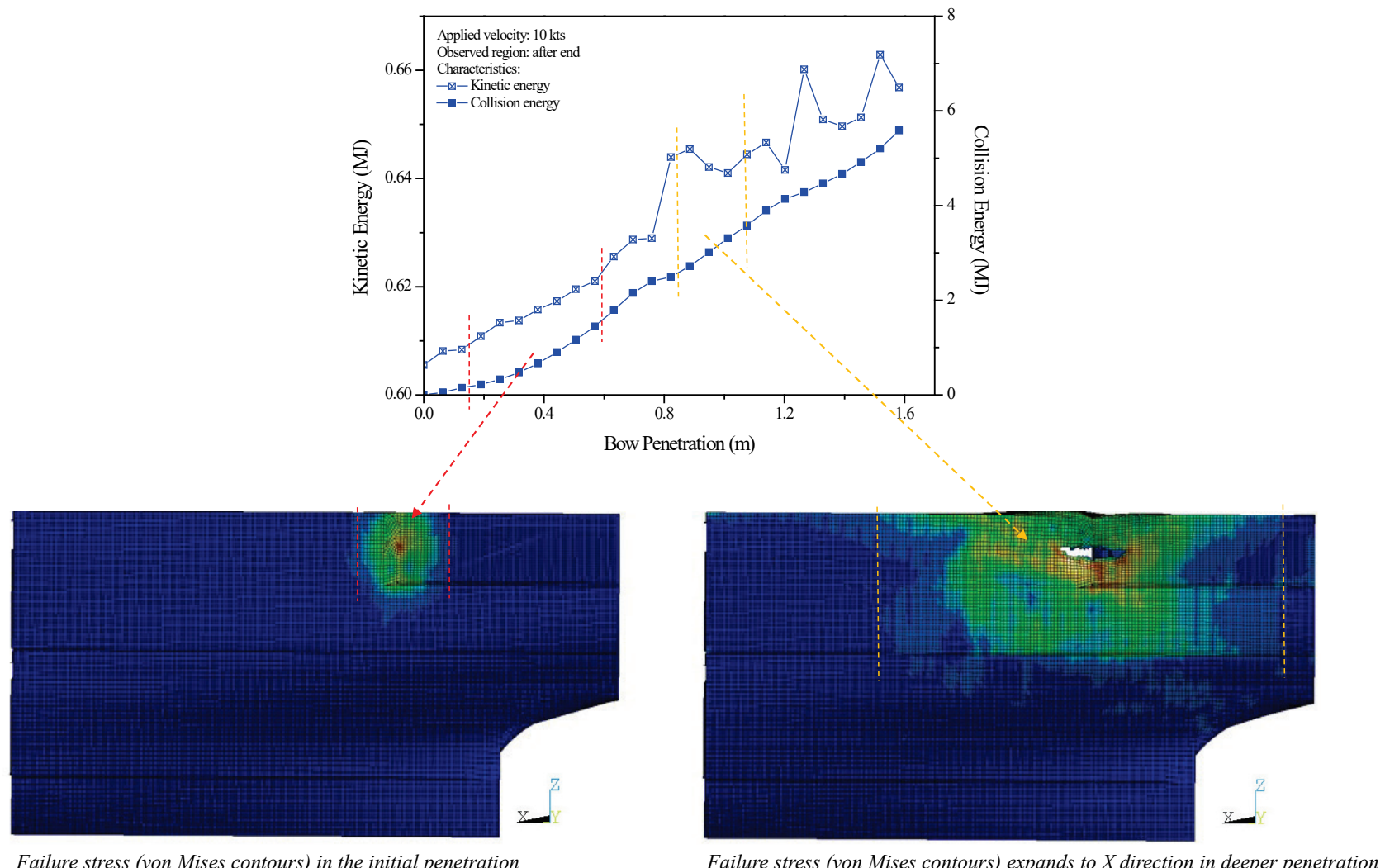

Figure 11 Failure stress during fluctuation period of the kinetic energy and increment of the collision energy

The damage extent, however, also produced inner contact of the side hull's components, e.g., side shell, main frame, web frame, middle deck, and main deck, during the collision process. The illustration of the inner contact process is presented in Appendix B. Before the impact happened, the side hull remained intact as shown in Fig. Ba. A moment after contact with the striking ship happened, the hull experienced plastic deformation (Fig. B-b) with the transverse components. For example, the web frame and main frame began to deflect in the coming direction of the striking ship, or $Y$-axis. As the absorbed strain energy (collision energy) surpassed the material strength, the hull structure began to rupture, and tearing occurred on the outer hull (Fig. B-c). The transverse structure is truncated in Fig. B-d, not long after the side hull experienced failure. The advance penetration of the striking ship on the struck ship caused the outer structure to receive massive damage where the main deck began to deform and middle deck was pushed by the striking ship and contacted with the frames. The destroyed parts of the transverse frames also contacted each other. However, from all observed scenarios, the inner hull, which is the final defence against side collision, only experienced rupture on one target point of the middle-hull and after-end regions. The fore-end region was the best in providing resistance during collision.

\section{CONCLUSIONS}

Several calculation results from the response of a struck ship when experiencing side collisions with the bow of a striking ship were presented. Parameters of the external dynamics, namely, location and velocity, were involved to build the proposed collision models. The observations in the study pointed to a remarkable phenomenon: the event sequence the side structure experienced during ship collision. The influence of the transverse framing system on the structural behaviour was found to be significant. In the same region, the characteristics of the damage and events sequence could be different, because the distances between two web frames were not the same. The contribution of the distance between the outer and inner hulls on the damage pattern can be considered a promising research opportunity.

Validation of the material configuration was also presented by comparing the collision energy with a pioneering work in ship collision. Material strength was concluded to be equally perpendicular to the collision energy, and, furthermore, the kinetic energy is also 
influenced. Harder material requires a higher kinetic energy to penetrate it under the assumption that the applied velocity on the striking ship is constant. Evaluation of the striking velocity resulted in a good correlation with the depth of penetration of the struck ship. The kinetic energy of the striking ship represented the resistance of the side structure when it was penetrated or even destroyed during the collision process. Because a constant velocity was applied in the analyses, the characteristic of the kinetic energy continued to climb as further penetration was experienced by the struck ship. If another scenario is used in which an initial velocity is deployed, it can be expected that the kinetic energy will decrease as the energy is absorbed by the side hull in the penetration process.

\section{Acknowledgement}

This work is successfully presented with the grant from BK21 plus MADEC Human Research Development Group, Republic of Korea.

\section{REFERENCES}

[1] Jones, N. (2013). Damage of plates due to impact, dynamic pressure and explosive loads. Latin American Journal of Solids and Structures, 10, 767-780. https://doi.org/10.1590/S1679-78252013000400006

[2] Prabowo, A. R., Bae, D. M., Sohn, J. M., \& Cao, B., (2016). Energy behavior on side structure in event of ship collision subjected to external parameters. Heliyon, 2(11). https://doi.org/10.1016/j.heliyon.2016.e00192

[3] Bae, D. M., Prabowo, A. R., Cao, B., Sohn, J. M., Zakki, A. F., \& Wang, Q. (2016). Numerical simulation for the collision between side structure and level ice in event of side impact scenario. Latin American Journal of Solids and Structures, 13, 2991-3004. https://doi.org/10.1590/1679-78252975

[4] Yip, T. L., Talley, W. K., \& Jin, D. (2011). The effectiveness of double hulls in reducing vessel-accident oil spillage. Marine Pollution Bulletin, 62, 2427-2432. https://doi.org/10.1016/j.marpolbul.2011.08.026

[5] Prabowo, A. R., Bae, D. M., Sohn, J. M., \& Zakki, A. F. (2016). Evaluating the parameter influence in the event of a ship collision based on the finite element method approach. International Journal of Technology, 4, 592-602. https://doi.org/10.14716/ijtech.v7i4.2104

[6] Lützen, M. (2001). Ship Collision Damage. Technical University of Denmark, Lyngby, Denmark.

[7] Ozguc, O., Das, P. K., \& Barltrop, N. (2005). A comparative study on the structural integrity of single and double skin bulk carriers under collision damage. Marine Structures, 18, 511-547. https://doi.org/10.1016/j.marstruc.2006.01.004

[8] Minorsky, V. U. (1958). An analysis of ship collision with reference to protection of nuclear power ships. Journal of Ship Research, 3, 1-4.

[9] Zhang, S. (1999). The Mechanics of Ship Collisions. Technical University of Denmark, Lyngby, Denmark.

[10] Mazzariol, L. M., Oshiro, R. E., \& Alves, M. (2016). A method to represent impacted structures using scaled models made of different materials. International Journal of Impact Engineering, 90, 81-94. https://doi.org/10.1016/j.ijimpeng.2015.11.018

[11] Oshiro, R. E., Calle, M. A. G., Mazzariol, L. M., \& Alves, M. (2017). Experimental study of collision in scaled naval structures. International Journal of Impact Engineering, 110, 149-161. https://doi.org/10.1016/j.jijmpeng.2017.01.024
[12] Paik, J. K. (2007). Practical techniques for finite element modeling to simulate structural crashworthiness in ship collisions and grounding (Part I: Theory). Ships and Offshore Structures, 2, 69-80. https://doi.org/10.1533/saos.2006.0148

[13] Paik, J. K. (2007). Practical techniques for finite element modelling to simulate structural crashworthiness in ship collisions and grounding (Part II: Verification). Ships and Offshore Structures, 2, 81-85. https://doi.org/10.1533/saos.2006.0149

[14] Calle, M. A. G., Oshiro, R. E., \& Alves, M. (2017). Ship collision and grounding: Scaled experiments and numerical analysis. International Journal of Impact Engineering, 103, 195-210. https://doi.org/10.1016/j.jijmpeng.2017.01.021

[15] Prabowo, A. R., Cao, B., Bae, D. M., Bae, S. Y., Zakki, A. F., \& Sohn, J. M. (2017). Structural analysis of the double bottom structure during ship grounding by finite element approach. Latin American Journal of Solids and Structures, 14, 1-18. https://doi.org/10.1590/1679-78253648

[16] Jones, N. (2009). Hazard assessments for extreme dynamic loadings. Latin American Journal of Solids and Structures, 6, 35-49.

[17] Bathe, K. J. (1996). Finite Element Procedures. Prentice Hall, New Jersey, US.

[18] Jones, N. (1989). Structural Impact. Cambridge University Press, Cambridge, UK.

[19] Cowper, G. R. \& Symonds, P. S. (1957). Strain hardening and strain rate effects in the impact loading of cantilever beams. Technical report no. 28. Brown University, Providence, US. https://doi.org/10.21236/AD0144762

[20] Paik, J. K. \& Thayambali, A. K. (2003). Ultimate Limit State Design of Steel-Plated Structures. Wiley, New Jersey, US.

[21] Törnqvist, R. (2003). Design of Crashworthy Ship Structures. Technical University of Denmark, Lyngby, Denmark.

[22] Alsos, H. S. \& Amdahl, J. (2009). On the resistance to penetration of stiffened plates, Part I - Experiments. International Journal of Impact Engineering, 36, 199-807. https://doi.org/10.1016/j.ijimpeng.2008.10.005

[23] Prabowo, A. R., Bae, D. M., Sohn, J. M., Zakki, A. F., Cao, B., \& Cho, J. H. (2017). Effects of the rebounding of a striking ship on structural crashworthiness during ship-ship collision. Thin-Walled Structures, 115, 225-239. https://doi.org/10.1016/j.tws.2017.02.022

[24] Simonsen, B. C. (1997). Mechanics of Ship Grounding. Technical University of Denmark, Lyngby, Denmark.

[25] Wang, G. (1995). Structural Analysis of Ship Collision and Grounding. University of Tokyo, Tokyo, Japan.

[26] Wen, H. M. \& Jones, N. (1993). Experimental investigation of the scaling laws for metal plates struck by large masses. International Journal of Impact Engineering, 13, 485-505. https://doi.org/10.1016/0734-743X(93)90120-V

[27] Bae, D. M., Prabowo, A. R., Cao, B., Zakki, A. F., \& Haryadi, G. D. (2016). Study on collision between two ships using selected parameters in collision simulation. Journal of Marine Science and Application, 15, 63-72. https://doi.org/10.1007/s11804-016-1341-2

[28] ANSYS, (2017). ANSYS LS-DYNA User's Guide. ANSYS Inc., Pennsylvania, US.

[29] Krieg, R. D. \& Key, S. W. (1976). Implementation of a time dependent plasticity theory into structural computer program, constitutive equation in viscoplasticity: computational and engineering aspects. American Society of Mechanical Engineers, 20, 125-137.

[30] Prabowo, A. R., Baek, S. J., Cho, H. J., Byeon, J. H., Bae, D. M., \& Sohn, J. M. (2017). The effectiveness of thin-walled hull structures against collision impact. Latin American Journal of Solids and Structures, 14, 1345-1360. https://doi.org/10.1590/1679-78253895

[31] Prabowo, A. R., Bae, D. M., Sohn, J. M., Zakki, A. F., Cao, B., \& Wang, Q. (2017). Analysis of structural behavior 
during collision event accounting for bow and side structure interaction. Theoretical and Applied Mechanics Letters, 7, 612. https://doi.org/10.1016/j.taml.2016.12.001

[32] Prabowo, A. R., Bae, D. M., Cho, J. H., \& Sohn, J. M (2017). Analysis of structural crashworthiness and estimating safety limit accounting for ship collisions on strait territory. Latin American Journal of Solids and Structures, 14, 1594-1613. https://doi.org/10.1590/1679-78253942

[33] Chen, D. (2000). Simplified Ship Collision Model. Virginia Polytechnic Institute and State University, Virginia, US.

[34] Prabowo, A. R., Bae, D. M., Sohn, J. M., Zakki, A. F., \& Cao, B. (2017). Rapid prediction of damage on a struck ship accounting for side impact scenario models. Open Engineering, 7, 91-99. https://doi.org/10.1515/eng-2017-0014

[35] Zhang, S. \& Pedersen, P. T. (2017). A method for ship collision damage and energy absorption analysis and its validation. Ships and Offshore Structures, 12, S11-S20. https://doi.org/10.1080/17445302.2016.1254584

\section{Contact information}

Dr. Eng. Aditya Rio PRABOWO, S.T., M.T., M. Eng

1) Interdisciplinary Program of Marine Convergence Design,

Pukyong National University,

Nam-gu, Yongso-ro 45, Daeyeon-dong, Busan 48513, South Korea

2) Department of Mechanical Engineering

Universitas Sebelas Maret,

JI. Ir. Sutami No.36A, Surakarta 57126, Central Java, Indonesia

E-mail: aditya@ft.uns.ac.id

\section{Prof. Jung Min SOHN}

(Corresponding author)

1) Interdisciplinary Program of Marine Convergence Design,

Pukyong National University,

Nam-gu, Yongso-ro 45, Daeyeon-dong, Busan 48513, South Korea

2) Department of Naval Architecture and Marine Systems Engineering,

Pukyong National University,

Nam-gu, Yongso-ro 45, Daeyeon-dong, Busan 48513, South Korea

E-mail: jminz@pknu.ac.kr

\section{Prof. Dong Myung BAE}

Department of Naval Architecture and Marine Systems Engineering, Pukyong National University,

Nam-gu, Yongso-ro 45, Daeyeon-dong, Busan 48513, South Korea

E-mail: dmbae@pknu.ac.kr

\section{Prof. Joung Hyung $\mathrm{CHO}$}

Interdisciplinary Program of Marine Convergence Design,

Pukyong National University,

Nam-gu, Yongso-ro 45, Daeyeon-dong, Busan 48513, South Korea

E-mail: jhcho7@pknu.ac.kr

\section{Appendix A}

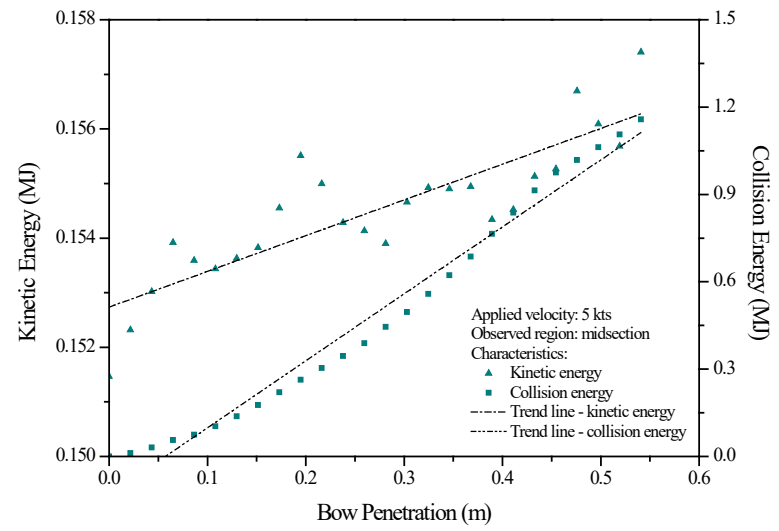

Figure A-1 Energy characteristic of the midsection with striking velocity $=5 \mathrm{kts}$

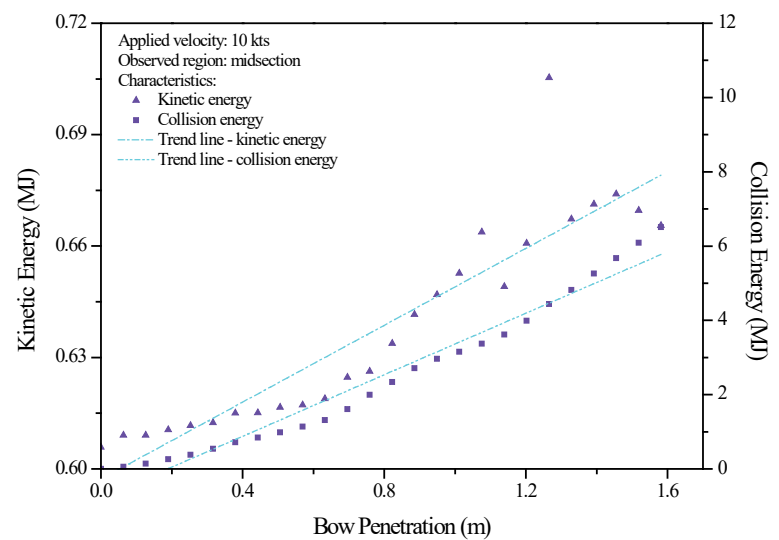

Figure A-2 Energy characteristic of the midsection with striking velocity = $10 \mathrm{kts}$

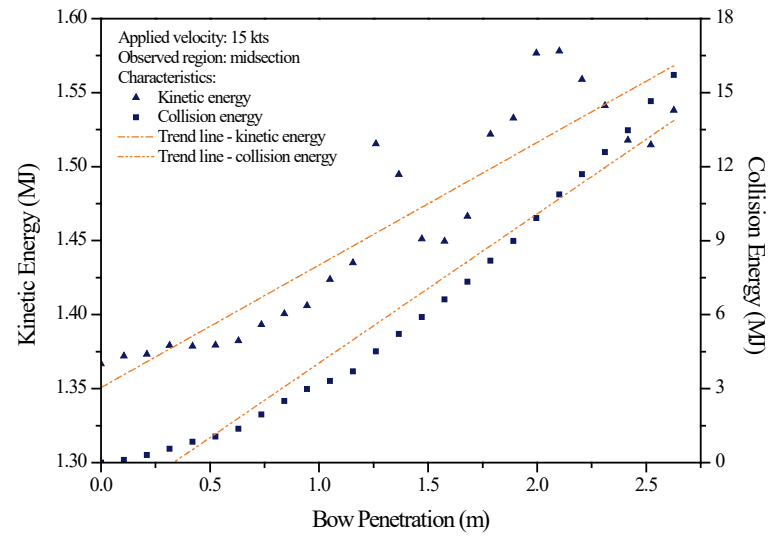

Figure A-3 Energy characteristic of the midsection with striking velocity = $15 \mathrm{kts}$

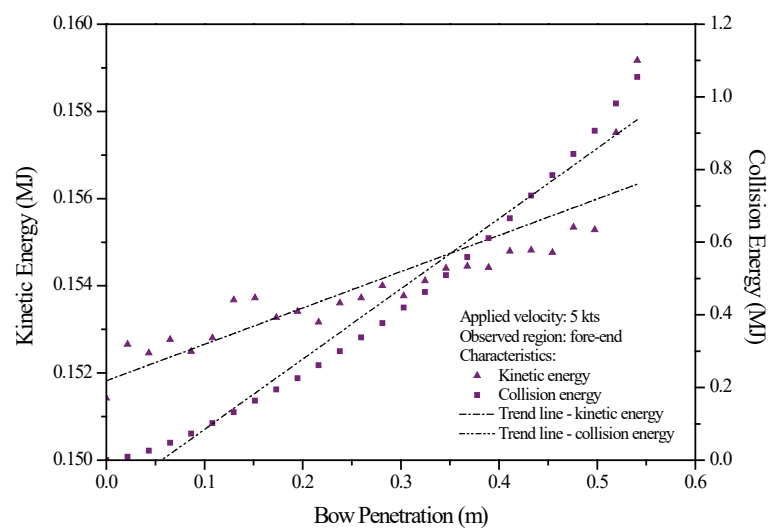

Figure A-4 Energy characteristic of the fore-end with striking velocity = $5 \mathrm{kts}$ 


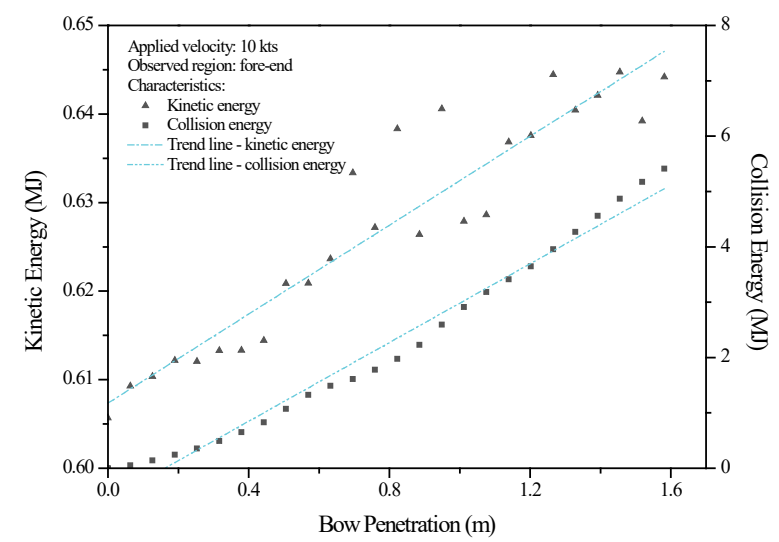

Figure A-5 Energy characteristic of the fore-end with striking velocity $=10 \mathrm{kts}$

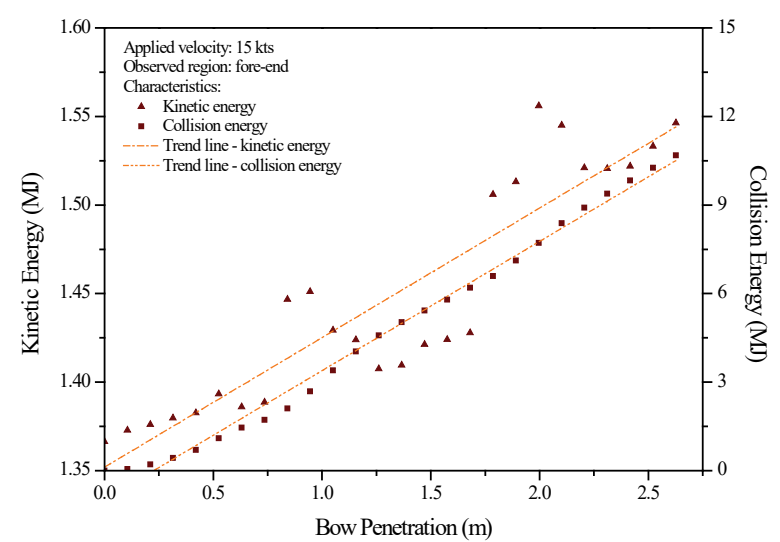

Figure A-6 Energy characteristic of the fore-end with striking velocity $=15 \mathrm{kts}$

\section{Appendix B}
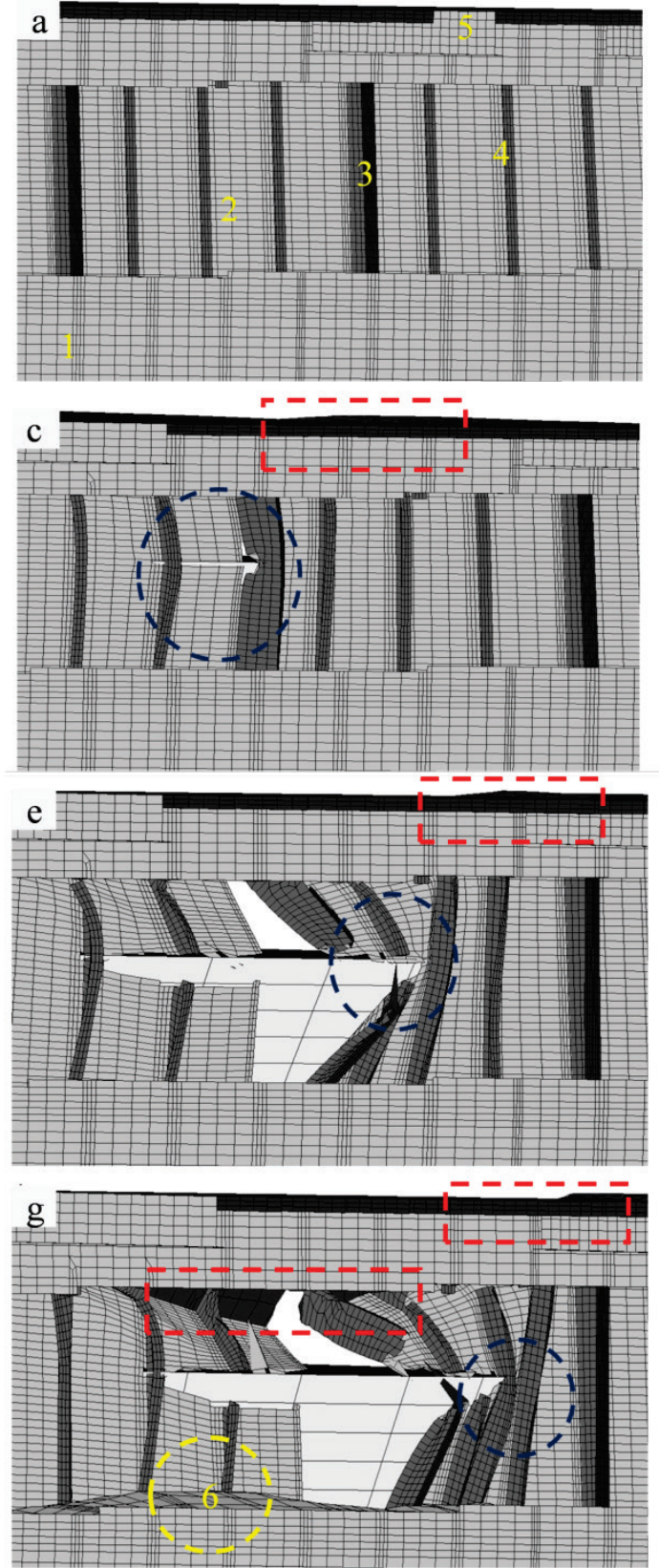
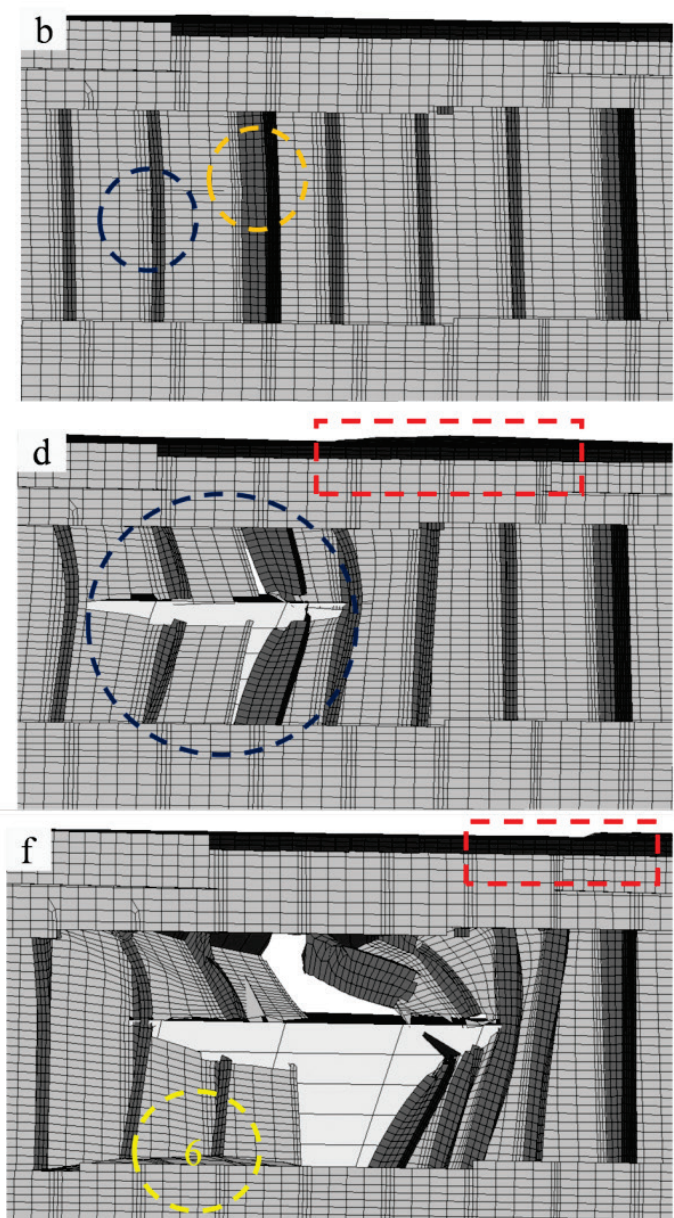

Components of the double hull structure:

1. Inner shell

2. Outer shell

3. Web frame

4. Main frame

5. Main deck

6. Middle deck

Figure B Component behaviour during inner contact took place due to bow penetration. Detail explanation regarding a series of structural failure is provided in Section 5.2 